\title{
Towards a Service System Ontology for Service Science
}

\author{
Elisah Lemey and Geert Poels \\ Center for Service Intelligence \\ Faculty of Economics and Business Administration \\ Ghent University \\ Tweekerkenstraat 2, 9000 Gent, Belgium \\ \{Elisah.Lemey, Geert.Poels\}@UGent.be
}

\begin{abstract}
.
Service Science is a new interdisciplinary approach to the study, design, implementation, and innovation of service systems. However due to the variety in service research, there is no consensus yet about the theoretical foundation of this domain. In this paper we clarify the service systems worldview proposed by Service Science researchers Spohrer and Kwan by investigating its foundational concepts from the perspective of established service theories and frameworks. By mapping the proposed service system concepts on the selected service theories and frameworks, we investigate their theoretical foundations, examine their proposed definitions and possible conflicting interpretations, discover their likely relationships and general structure, and identify a number of issues that need further discussion and elaboration. This analysis is visualised in a multi-view conceptual model (in the form of a UML class diagram) which we regard as a first step towards an explicitly and formally defined service system ontology.
\end{abstract}

Keywords: Service Science, SSME, service system, conceptual analysis, conceptual modelling, ontology, service-dominant ontology, systems theory

\section{Introduction}

Service Science is a new interdisciplinary field that studies the structure and behaviour of service systems. A lot of suggestions have been made about which theories can serve as a basis for Service Science research or which frameworks can be used to conceptualize the object of study of Service Science, but few consensus exists among different authors [1-3]. This lack of agreement may become an obstacle for the further development of the Service Science research field.

Recently, Spohrer and Kwan [4] proposed the service systems worldview as a candidate shared conceptualization for Service Science researchers. Although the concepts of this worldview are not new, their theoretical foundation was not clarified by Spohrer and Kwan. 
To foster the discussion of the appropriateness of the proposed service system conceptualisation this paper investigates the proposed concepts from the perspective of established service theories and frameworks from traditional service research areas as service marketing, service management, service operations and service computing. Based on this investigation, we also identify relationships between the concepts proposed for this worldview and visualise the identified structures in a conceptual model (in the form of a UML class diagram).

The basis for the model are the ten foundational concepts of the service systems worldview. The definitions of these concepts are compared with alternative definitions originating in six other service frameworks and theories. We aim to identify which additional concepts from these theories and frameworks can be incorporated in the model to further refine and extend the service systems worldview. By mapping the foundational concepts to the concepts used in traditional service research areas we identify commonalities and differences in interpretation which may help to find a common understanding of the service systems worldview. Also, if we want to create one scientific basis for Service Science research it is crucial that established service frameworks and theories connect to this scientific basis.

Our contribution to the emerging research area of Service Science is twofold. First of all, a UML class diagram for the ten foundational concepts is presented. This diagram is aimed at facilitating the presentation and discussion of the foundational concepts as it also uncovers and shows their relationships. The diagram provides the basis for elaborating a service systems ontology and a meta-model for modelling of service systems. Second, the investigation of the theoretical foundation (if any) and the search for additional concepts which can be marked as foundational, can be seen as a theoretical evaluation of the completeness and relevancy of the set of foundational concepts proposed by Spohrer and Kwan [4]. It provides elements for the further discussion, enhancement, and ultimately (and hopefully) consensual agreement of a service systems conceptualisation for Service Science.

Section 2 presents the service systems worldview as proposed by Spohrer and Kwan [4]. Section 3 gives an overview and motivates our choice of the service theories and frameworks used in the research. Section 4 presents the mapping of the foundational concepts of the service systems worldview to the concepts of the chosen service theories and frameworks. It also explains the development of the conceptual model based on the mapping results and discovery of concept relationships. Section 5 then discusses the main findings of our theoretical investigation of the service systems worldview. Section 6 presents conclusions and future work.

\section{Foundational Concepts of the Service Systems Worldview}

Spohrer and Kwan [4] use ten foundational concepts to explain the diversity and complexity of service systems: entity, resource, access right, ecology, interaction, value proposition based interaction, governance mechanism based interaction, outcome, measure, and stakeholder. To introduce these concepts in this paper we 
developed a UML class diagram (Figure 1). The use of a visual conceptual model will also facilitate the analysis of the foundational concepts (see section 4).

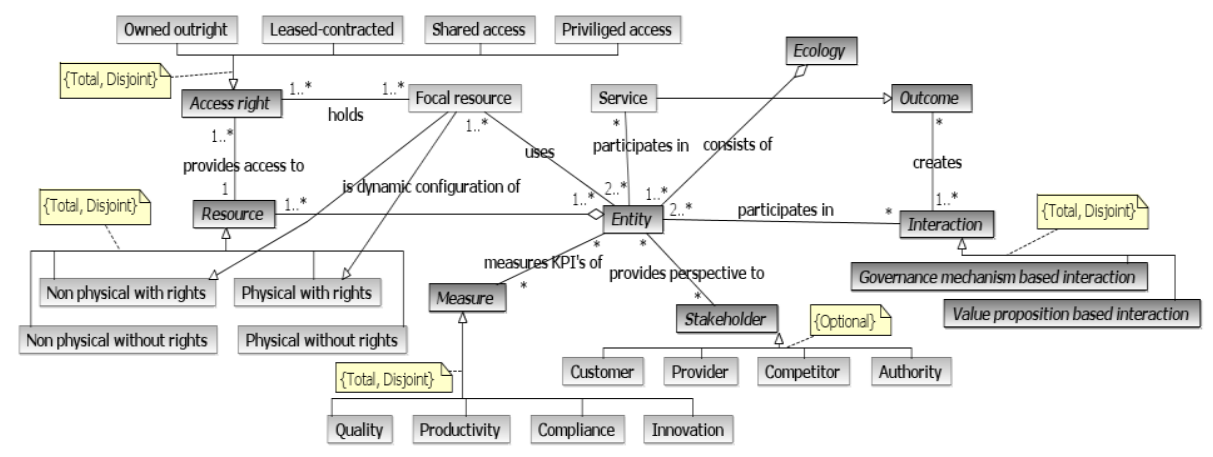

Fig. 1. UML class diagram of service systems worldview

A service system entity is a dynamic configuration of resources. There are four types of resources: physical with rights (people), physical without rights (technology, natural resources), non-physical with rights (organisations), and non-physical without rights (shared information). In each service system entity there is at least one focal resource that holds access rights to the other resources in the configuration. Different types of access rights are owned outright, leased-contracted, shared access, and privileged access [5].

The environment in which service system entities operate is the service system ecology. It is the sum of all macro-scale interactions of the population of all service system entities. It is characterized by both the diversity and the amount of types of service system entities [6]. Two main types of service system entities can be distinguished: formal entities that exist within a legal and economic context and are formed by contracts and informal entities that are based on promises and can be situated in a social or political context. Service system entities can thus be people, families, companies, universities, organisations, cities or anything else that can interact with other service system entities [7].

Service system entities participate in interactions. It is through these interactions that service system entities improve their state. Thus, the purpose of these interactions is to create value [5]. The service systems worldview advocates mutual value cocreation [8]. Co-creation means that both entities are needed to create value. Mutual means that, service system entities will only create value for another entity if they are getting value out of it themselves. There are two types of interactions. When entities interact through value propositions, this is called a value proposition based interaction. A value proposition is a type of shared understanding between service system entities about how interactions between them can lead to mutual value cocreation [5]. Contrary to this type of interaction which is focused on voluntary reciprocal action of individual entities, the second type of interaction, governance mechanism based interaction, occurs in the context of collective interest, i.e., when 
the interaction is regulated by a governing body. Auctions and court cases are typical examples of this second type of interaction [4].

Interactions between service system entities lead to outcomes. When two or more service system entities interact, the outcome will be judged by each entity to determine whether value for that entity was created or not. The service systems worldview proposes the Interact-Service-Propose-Agree-Realize (ISPAR) model that models ten possible outcomes for interactions [8]. The ISPAR model indicates that the service systems worldview is not a happy path theory but also takes into account other outcomes that deviate from mutual value co-creation.

The service systems worldview further reckons that the interaction outcomes and their effect on the state of the participating service system entities have to be measured. Therefore, four types of measures are defined: quality, productivity, legal compliance, and sustainable innovation. These four measures serve as key performance indicators (KPI's) for a service system entity [5].

Next, all service system entities can view themselves and can be viewed from multiple stakeholder perspectives. The four main types of stakeholder perspectives are customer, provider, authority, and competitor. These types refer to roles that service system entities play in service system networks that are determined by the patterns of interactions between the participating service system entities.

We added service as an additional concept to the model. It seems only logical that a model of service systems includes the notion of service even if service is not one of the ten foundational concepts of the service systems worldview. According to the ISPAR model in the service systems worldview, mutual value co-creation that is the preferred outcome of interactions between service system entities is what is called service. For a service the resources of at least two service system entities are needed [8].

\section{Overview of Service Theories and Frameworks}

The large variety in service literature provides us with a rich network of conceptual pieces for the constructs described above. However, this variety at the same time brings along a complexity dimension because there is a lack of agreement between the different service theories. Note that in the remainder of this section (and the paper) we will use the term 'theory' to refer also to proposals that are more appropriately called 'framework' as they offer interrelated concepts to define and organise the service domain without purporting to have explanatory or predictive power.

Our choice of theories was mainly guided by previous Service Science research. In a joint white paper of IBM and Cambridge University's Institute for Manufacturing the worldview of Service Dominant Logic (SDL) is indicated as a possible theoretical basis for Service Science [1]. Furthermore, other proponents of Service Science propose the Unified Service Theory (UST), the work system method and the service quality gaps model as interesting theories to draw from for the elaboration of the Service Science discipline [9-11]. As recent Service Science research indicates the need to introduce a system focus in the study of service systems, we also included the 
system theoretic view of service systems of Mora et al. [12-13]. Finally, we included a service ontology based on the DOLCE upper-level ontology [14]. Although this ontological theory may not be as well-known in service research as the other theories, we believe that the insights of this ontological analysis are valuable. As it shows how a service ontology can be defined as a specialisation of a philosophical ontology describing the world in general, it can serve as an example for our own (future) research. We will give a description of each theory as an introduction to the reader.

First, $S D L$ advocates that service is the fundamental unit of exchange. A service is defined as "the application of specialized competences through deeds, processes and performances for the benefit of another entity or the entity itself". This implies that SDL does not focus on the products that are produced but on the value creating processes that accompany the consumption of the product and that deliver the actual value to the customer [15-17].

Second, UST focuses on the service process and states that every provider process in which an individual customer input can be identified is a service. Customers thus act as suppliers in the service process. They can offer themselves, their property or information as input. The unique contribution of this theory is in defining the concept of customer input [18].

Third, work system method and related concepts form the basis of a businessoriented system analysis and design tool. The work system framework uses nine basic elements to provide a system view of the organisation. The service value chain framework elaborates the work system framework with service-oriented insights. It presents a two-sided view of the service process as the service is coproduced by customer and provider. The work system life cycle model evaluates the change of work systems over time $[2,19]$.

Fourth, the service quality gaps model is designed to measure the quality of services. The starting point of the model is the assumption that there exists a gap between the quality perception of a company's management team and that of the customers. The model identifies four gaps on the side of the provider which combine into a fifth gap on the side of the customer: a gap between the expected service quality and the perceived service quality [20].

Fifth, the system theoretic approach of Mora et al. shows a systems view in which service systems are part of larger supra-systems and are composed themselves of service sub-systems [13]. There are two types of service sub-systems defined. The service facilitator represents the original service provider and the service appraiser represents the initial user's system. The supra-system further contains all environmental elements such as competitors, customers, regulators, suppliers or partners. An important feature of the model is that the supra-system is influenced by the value outcomes of its service (sub-)systems.

Sixth, the service ontology based on the DOLCE upper-level ontology of Ferrario and Guarino provides a general ontological foundation for service systems [14]. A service is conceived as a complex event with five main parts: service commitment, service presentation, service acquisition, service process and service value exchange. A key concept in this service ontology is the commitment of an agent to guarantee the execution of a service at a certain place and time. 


\section{Analysis}

For the analysis of the foundational concepts in the light of the above described theories, we start from Figure 1. The concepts of this model will be mapped subsequently on each service theory identified in the previous section. We have developed UML class diagrams for representing the concepts (and their relationships) underlying each theory to facilitate the mapping process. These diagrams can be interpreted as different views that overlay the conceptual model represented by the UML class diagram in Figure 1, where each view defines, refines and/or extends the foundational concepts from the perspective of the concerned theory. Although the foundational concepts can be compared to any of these theories in arbitrary order, we present our analysis results in an incremental manner focusing on the most remarkable interpretations and additions brought about by the different theories.

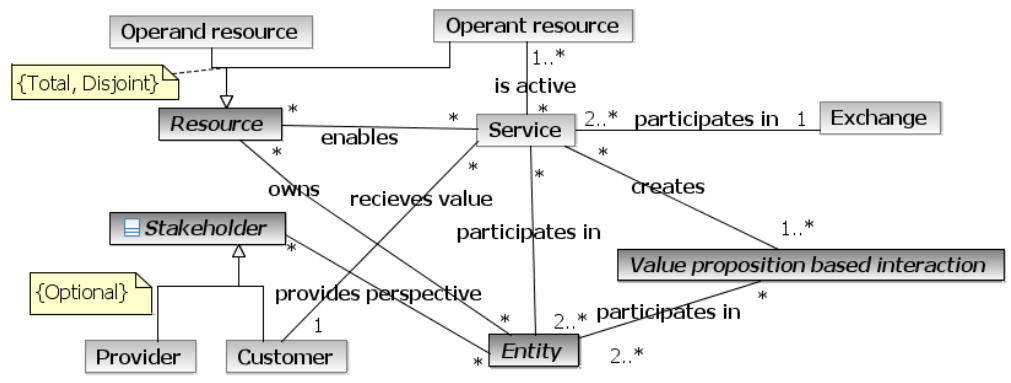

Fig. 2. UML class diagram of Service Dominant Logic

First of all, the service systems worldview embraces the ideas of SDL (Figure 2) which is proposed as its philosophical foundation [1]. However, not all foundational concepts can be grounded in SDL as this theory has no definition of the concepts ecology, governance mechanism based interaction, measure, and access right. Moreover, SDL is a happy path theory and therefore the concept outcome is narrowed down to value co-creation. As value co-creation is the only possible service outcome, it can be equated with service in Figure 2. SDL also indicates that there is only one beneficiary of the service, i.e., the customer [17]. Both SDL and service systems worldview state that a service implies the participation of at least two entities but according to SDL this doesn't imply mutual value creation. As explained, the value is co-created but only for the customer and thus economic exchange is needed for mutuality [15]. Therefore exchange is shown as a separate concept in the UML class diagram in Figure 2 whereas it was embedded in the service concept in Figure 1.The specification of the concept resource is also different. SDL differentiates between operand and operant resources. Operand resources such as commodities, buildings or tools are passive resources on which an operation or activity is performed to produce an effect. Operant resources such as competences or knowledge are employed to act upon operand resources and other operant resources [15]. SDL implies that at least one operant resource is active in the service. 


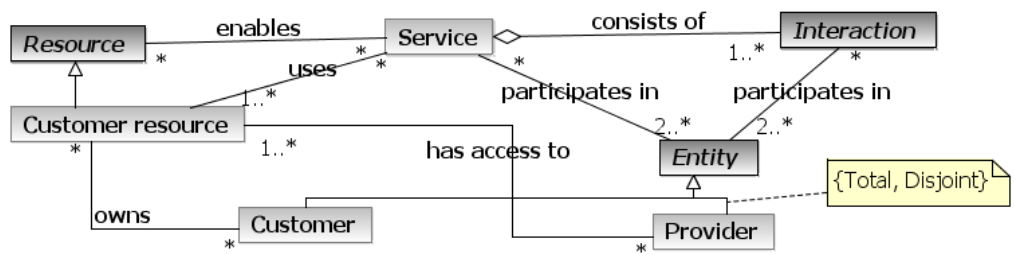

Fig. 3. UML class diagram of the Unified Service Theory

Second, UST takes a service operations perspective in which there is a strong focus on the concepts related to the service process (Figure 3). A service is perceived as a process that consists of (at least one) interactions between customer and provider. Furthermore, the theory introduces the concept customer resources which include customer-self inputs, tangible belongings and customer-provided information [18]. According to UST a service is a production process in which the customer provides at least one resource that is an essential input for the production of the service. This implies an extra constraint on the relationship between customer resource and provider. The provider has to have access to the customer resource(s) that are used as production input. This customer involvement also manifests itself in the notion of coproduction. Co-production implies not only participation of two service system entities (i.e., co-creation) but also the active involvement of the customer in the production process by contributing at least one customer resource.

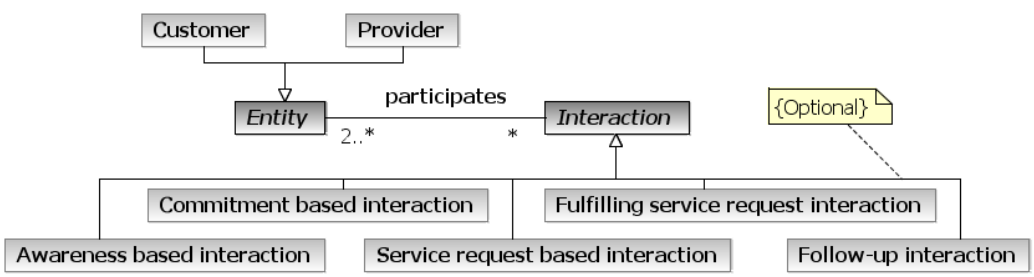

Fig. 4. UML class diagram of the work system method

Third, Alter's work system method also implies a process focus. The added value of this theory is in the service value chain. It shows the different steps that should be executed in a service process [2]. Alter shows the different kinds of interactions that emanate from a value proposition (Figure 4). First, customer-provider contact is based on awareness. The provider should create awareness among customers about the existence of the service. The customer should become aware of a need that has to be filled. Next, provider and customer will engage in a negotiation about commitment to the service. The ISPAR model of the service systems worldview also recognizes these two types of interaction (i.e., proposal and agreement) which show how the service process is initiated, but does not further distinguish between different types of interaction that occur when the rest of the service process is executed (i.e., realisation). The service value chain model further defines these interactions or 
'service encounters'. The customer makes a service request which is handled and fulfilled by the provider and the customer participates in this fulfilment. Finally, both customer and provider follow up the handling of the service.

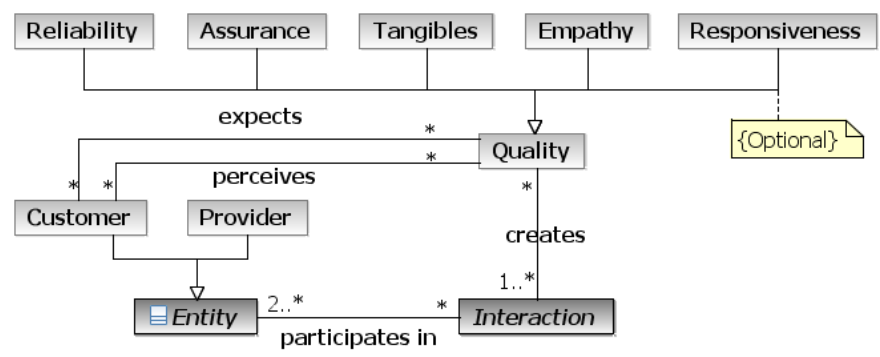

Fig. 5. UML class diagram of service quality gaps model

Fourth, the service quality gaps model was designed as an instrument to measure service quality. The contribution of the model is in the definition of five determinants of quality that serve as measures: reliability, assurance, tangibles, empathy, and responsiveness (Figure 5). It should be noted that the customer is the central stakeholder in the service quality gaps model. Therefore only the expected and the perceived quality from the viewpoint of the customer are taken into account. This is similar to the service systems worldview where the quality measure should be evaluated by service system entities in the role of customer [5]. A difference with quality as a measure in the service systems worldview is that quality is considered in relationship to services (as manifested by interactions between customer and provider) whereas in the service systems worldview it is a KPI of the service system entity in the role of provider.

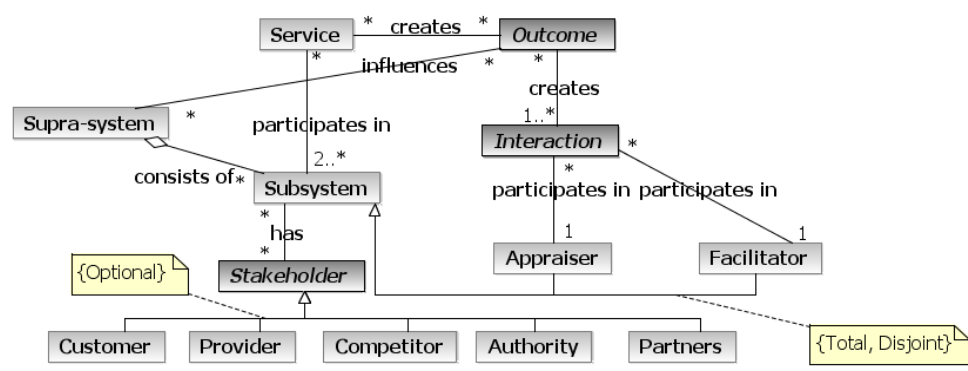

Fig. 6. UML class diagram of the systems theoretic model of Mora et al. [13]

Fifth, the systems theoretic model of Mora et. al. [13] defines a supra-system which corresponds with the ecology foundational concept and a sub-system which corresponds with the service system entity foundational concept (Figure 6). The supra-system consists of all stakeholders such as competitors, customers, authorities, providers or partners. An original insight from this model is that the supra-system is 
also influenced by the outcome of the interactions between the appraiser and facilitator subsystems. This outcome is defined as a change in the service properties in both the appraiser and facilitator subsystems. The systems theoretic model also accounts for service failure. The vision of Mora et. al. on service is very similar to that of the service systems worldview. Especially the explicit recognition of the service system ecology as the supra-system in which interactions between appraiser and facilitator sub-systems take place, shows the significant resemblance between the two models. This recognition also indicates an outward focus of the model. When a service is performed, it brings along changes not only for the participants of that service but also for the surrounding system.

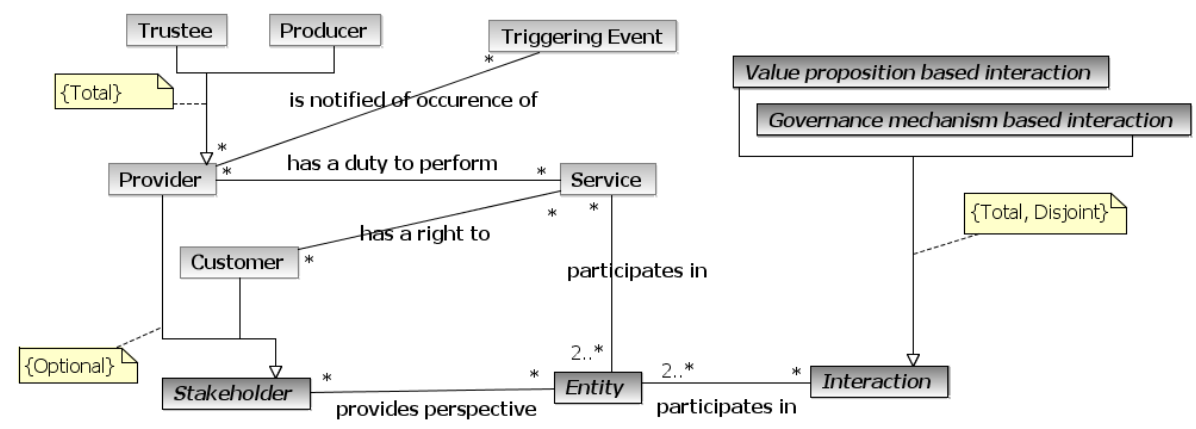

Fig. 7. UML class diagram of the service ontology of Ferrario and Guarino [14]

Sixth, the service ontology of Ferrario and Guarino [14] also elaborates the concept of interaction (Figure 7). The authors strongly focus on the concept of commitment which they consider as the core of a service. However, commitment here has a different meaning than commitment defined by Alter. Here commitment implies more than just offering a value proposition. A value proposition is usually the result of negotiations between provider and customer. Therefore the customer has already decided he wants a certain service. Service commitment according to Ferrario and Guarino means the willingness to perform a service on the side of the service provider without needing the involvement of the customer. This implies that service can exist even before the occurrence of interactions between provider and customer. Nevertheless, commitment is not sufficient to initiate the actual service execution as it only indicates willingness on the side of the provider. Hence, a triggering event is included. Provider entities should be notified of the occurrence of this event in order to know when the service should be executed. To the specification of the provider, the concept of trustee is added. The authors indicate that the entity that makes a commitment is not always the producer of the service. This distinction brings a sense of reality into the service ontology as real life services are often realized with more than two entities participating. Lastly, the service ontology provides us with a legal perspective on the service. It defines the right to a service which can be considered as an object and is, in contrast to the service, transferable. When a customer has a right to a service, the provider has a duty to perform this service. This duty to perform a 
service can also be transferred. The essence of the service process is not the service itself but the normative position of the participants in the service process.

\section{Discussion}

A core set of three foundational concepts is supported by all service theories used in the analysis: service system entity, interaction, and stakeholder perspective (or role played by the entity in the interaction). Although not all analysed service theories explicitly mentioned the concept of stakeholder, all theories support the view that it is essential for the service activity to have interactions between provider and customer entities. This implies that the ontological classification of service as an activity rather than an object is a feature that unites the service theories considered and the service systems worldview that is proposed for Service Science. The service ontology of Ferrario and Guarino provides us with a specification of the provider concept and distinguishes between service trustee and producer, where the former may delegate the service activity to the latter. This is an interesting perspective which does not contradict the service systems worldview as Spohrer and Kwan do not claim to have enumerated all possible stakeholder perspectives. The recognition of this distinction may however account for phenomena such as service outsourcing or subcontracting with an associated legal perspective. This may prove useful for the study of service systems.

The other foundational concepts are supported by only some of the service theories. Given that each service theory considers a particular scope within the service domain, this is not a problem per se as long as theories do not explicitly reject the existence of the concepts falling outside their scope. For instance, SDL only recognizes value proposition based interactions, but does not refute governance mechanism based interactions. The interactions described in the service value chain framework of the work system method are also value proposition based and implicitly this type of interaction is assumed by the service quality gaps model, so there seems to be sufficient support for this type of interaction. The service commitment in the service ontology of Ferrario and Guarino can be a value proposition based interaction or a governance mechanism based interaction, e.g., a newly founded state university commits to the government of the state to provide education to its citizens once it becomes operational.

Another foundational concept for which support can be found in several of the discussed theories is resource. The service systems worldview defines service system entities as configurations of resources. Service entails interactions between a provider and customer entity, implying that resources of both entities are involved (e.g., consumed, used, applied, employed,..). For the provider resources in the service this implies that at least one focal resource of the provider entity is involved as this focal resource has access rights to other provider resources that might be needed. The service systems worldview distinction of resources 'with rights' versus 'without rights' is largely similar to the distinction 'operant' versus 'operand' in SDL so the involvement of a focal, hence operant resource of the provider in the service thus conforms to SDL. What is less clear in the service systems worldview is the involvement of customer resources. Here, both SDL and UST can shed some light, 
though in different and possibly contradicting ways. UST requires the involvement of at least one customer resource, which can be physical or non-physical, operand (without rights) or operant (with rights), as an input to the production of the service. SDL does also require the involvement of at least one customer resource, though not necessarily as an input to the service production. This difference, which can also be captured by the distinction between co-production (UST) and co-creation of value (SDL), is important and leads to a different view of service.

UST recognizes the existence of other processes than service processes, e.g., production processes aimed at mass production of commodities, whereas SDL rejects any other economic activity than service activity. Even the buying of mass produced commodities without providing any individual input to the production process is considered as service exchange because the value that the customer gets results from using these commodities (i.e., integrating it with other customer resources in SDL speak). This difference has important consequences for the service systems worldview. As SDL is proposed as the philosophical foundation of Service Science [1], the service systems worldview tends towards the co-creation view. If SDL is followed then the logical consequence is that all economic activity must be service. In this case a further specification of the nature of the involvement of customer resources and the implications for value is desired. If, however, value co-creation is interpreted as co-production as in UST then not all economic activity would qualify as service activity. If this would be agreed upon, the concept of value co-creation needs to be redefined. Even in that case, the nature of the involvement of customer resources needs to be specified further.

The foundational concept of access right seems to be a derivative concept (hence we can question its qualification as foundational), but is certainly useful for further describing what is meant by an entity as a configuration of resources. If value cocreation would be redefined using UST (so more as co-production), then the access right concept can be further founded on this theory, specifically with respect to the provider entity having access to customer resources that are input to the service process.

The concept of ecology can be founded on the notion of supra-system as in the system theoretic model of Mora et al. This concept is not explicitly present in the other theories discussed, although the service ontology of Ferrario and Guarino recognizes the existence of a broader societal and legal context in which service takes place (hence the presence of service commitment as a governance mechanism based interaction). Interesting in the system theoretic model is the link between interaction outcomes and the supra-system showing that the favourable or unfavourable outcomes of service interactions affect and are affected by the ecology in which the participating service system entities reside. The explicit recognition of such a relationship may be useful for the study of service systems.

The favourable outcome according to the service systems worldview is mutual value co-creation, which is also the view of SDL. However, in SDL mutual value cocreation is the only outcome explicitly recognized. The system theoretic model recognizes that there might be other, unfavourable outcomes. The service quality gaps model does also given that a gap can exist between the expected and perceived outcome, which should be quality according to this model.

This brings us to the last foundational concept to discuss, measure. The measure 
concept and its specialisation into four kinds of performance indicators for a service system entity is not directly supported by the service theories used in the analysis. The service quality gaps model focuses on quality measures where quality is one of these four dimensions. However, it considers quality in relation to individual or sets of service interactions and not to the performance of the service system entity as a whole. Of course, quality assessments of service interactions do provide an indication of the quality of the service provider itself. For the other three dimensions (productivity, compliance, innovation) a theoretical foundation must be found elsewhere.

An interesting difference and possible point of discussion for the service systems worldview is what is not explicitly defined in any of the different model views and that is the concept of service system itself. One point of view is that the service system is described by the entirety of the concepts and their relationships. But even then, important differences between the service theories pop up. Table 1 tries to answer the question 'what is the service system?' for the discussed theories and the proposed service systems worldview by looking at different dichotomies that were derived from the analysis in the previous section. The table shows that the theories roughly fall apart in two categories: those with an outward focus implying that services are positioned within and have effect on a broader context, which is considered as the service system, and those with an inward focus implying that services take place between and have an effect on their participants, which are considered as the service systems. The inward focus category is made up of SDL, which is clearly its prime representant, and further also the work system and service quality gaps model. The UST leans towards the inward focus, but takes a somewhat special position as it strongly emphasizes the service process happening within the service system that is in the provider role [21]. To the outward focus category belong the system theoretic model and to a lesser extent the service ontology. Although conceptual research in Service Science that preceded the proposal of the service systems worldview can clearly be characterized by an inward focus because of its embracing of SDL as philosophical foundation, our analysis shows that the set of foundational concepts as proposed by Spohrer and Kwan clearly tends towards an outward focus as it fits well with the system theoretic model of Mora et al. This result is an interesting point of discussion as it might imply that the service system conceptualisation put forward is focusing now on its systems foundation after having developed its SDL-based service foundation.

Finally, we already remarked that service itself is not defined as a foundational concept in the service systems worldview; we added it ourselves as an eleventh, potentially foundational concept to the model represented by the class diagram in Figure 1. It is remarkable that few service theories discussed provide an explicit definition of service; SDL and the service ontology by Ferrario and Guarino being notable exceptions. Nevertheless, the notion of service as viewed upon by a certain theory can mostly be derived from the definitions and relationships of the concepts that are explicitly defined. Based on our analysis we can distil three main perspectives: process-oriented, outcome-oriented and commitment-oriented which are presented in figure.8. 
Table 1. What is a service system?

\begin{tabular}{|c|c|c|c|c|c|c|c|}
\hline & Service system worldview & SDL & UST & work system method & service quality gaps model & system theoretic model & I service ontology \\
\hline \multicolumn{8}{|c|}{ Closer to the notion of ecology (or a subset of it as the notion of ecology can be defined recursively) or closer to the notion of service system entity? } \\
\hline Ecology & & & & & & $\Leftrightarrow$ & \\
\hline Entity & & $\Rightarrow$ & $\Rightarrow$ & $\Rightarrow$ & $\Rightarrow$ & & $\Rightarrow$ \\
\hline \multicolumn{8}{|c|}{ Value creation or production interactions occur within the service system or between the service systems? } \\
\hline Within & $\Leftrightarrow$ & & $\Leftrightarrow$ & & & $\Leftrightarrow$ & \\
\hline Between & & $\Rightarrow$ & & $\Rightarrow$ & $\Rightarrow$ & & $\Rightarrow$ \\
\hline \multicolumn{8}{|c|}{ Mutuality occurs within a service system or between service systems (implying economic exchange between service systems)? } \\
\hline Within & $\Leftrightarrow$ & & & & & $\Leftrightarrow$ & \\
\hline Between & & $\Rightarrow$ & & & & & \\
\hline \multicolumn{8}{|c|}{ Also governance mechanism based interactions or only value proposition based interactions? } \\
\hline Governance mechanism & $\Leftrightarrow$ & & & & & & $\Leftrightarrow$ \\
\hline Only value based & & $\Rightarrow$ & $\Rightarrow$ & $\Rightarrow$ & $\Rightarrow$ & & \\
\hline \multicolumn{8}{|c|}{ Many kinds of stakeholder perspectives or only explicit recognition of provider-customer roles? } \\
\hline Many kinds & $\Leftrightarrow$ & & & & & $\Leftrightarrow$ & $\Leftrightarrow$ \\
\hline Only provider-customer & & $\Rightarrow$ & $\Rightarrow$ & $\Rightarrow$ & $\Rightarrow$ & & \\
\hline
\end{tabular}

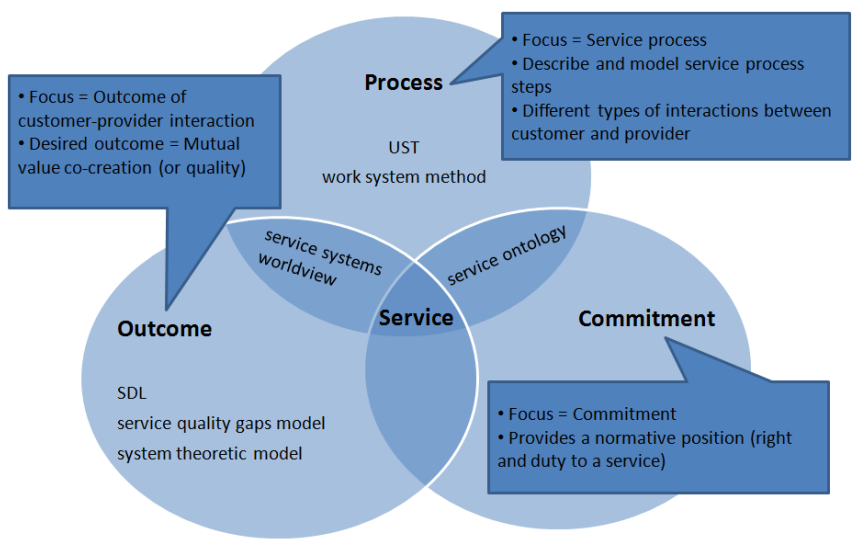

Fig. 8. Three perspectives on service

Four of the analyzed theories have a process orientation. First, the service value chain framework of the work system method distinguishes and sequences five different provider-customer types of interaction (see Figure 4). Also the service ontology of Ferrario and Guarino distinguishes between different phases that can be related to a service as a process view. Next, UST is clearly a process-oriented theory but focuses on customer inputs rather than on interactions between customer and provider. Finally, the ISPAR model related to the service systems worldview recognizes three types of service interaction i.e., proposal, agreement, and realisation.

The service systems worldview, SDL, the service quality gaps model and the system theoretic model of Mora et al. are outcome-oriented. For SDL this outcome is mutual value co-creation where the mutuality is established through economic exchange (i.e., service-for-service) and the co-creation is realized through resource integration by the customer. For the service quality gaps model the outcome is the quality of the service as perceived by the customer. For the system theoretic model the desired outcome is the improvement of the state of the appraiser and facilitator sub-systems (i.e., the consumer and provider entities), which affects the state of the 
service system and its supra-system (i.e., the ecology). The service systems worldview of Spohrer and Kwan shares the desired outcome of service as mutual value co-creation with SDL, though mutuality may here reside within the service (as in the system theoretic model of Mora et al.) rather than in the economic exchange of services. With the system theoretic model it shares the goal of service interactions as expressed by improvements in the state of the participating service system entities. Also the observation that the desired outcomes are not always achieved is shared with the systems theoretic model.

The commitment-oriented perspective refers to the service ontology of Ferrario and Guarino, which distinguishes between the service process (as discussed above under process-oriented) and the service itself. The service ontology takes a unique position by defining service as a commitment between a provider and a customer or a governance body that acts in the interests of (future) customers. The service as commitment view allows service to exist even without interactions taking place between the provider and the customer. The commitment is an interaction, but does not necessarily involve the customer and this position was not found in the other service theories discussed, neither is it part of the service systems worldview.

\section{Conclusion and future work}

In this paper we investigated whether the service systems worldview of Spohrer and Kwan can be founded on established service theories and frameworks. Our research points out that more or less all of the foundational concepts and their proposed specialisations are covered by one, many or in some cases even all reviewed service theories or frameworks. We identified a couple of issues that need further discussion and elaboration, e.g., because of conflicting views when mapping foundational concepts to the concepts of different service theories. Overall, however, our analysis shows that there is evidence of theoretical support for the proposed service systems worldview.

An interesting finding is that, although SDL was initially proposed as the philosophical foundation for the service systems worldview, our analysis indicates that the service system conceptualisation put forward by Spohrer and Kwan is developing beyond SDL. The resemblance with the system theoretic approach of Mora et al. shows a shift towards systems thinking which should be further explored in the future.

Future research may develop in two directions. First, the UML class diagrams developed in this paper can be used as a basis for the further formalisation of the service systems worldview into a service systems ontology. The availability of a consensually agreed ontology could take Service Science a big step forwards as the integrative nature of the research intended by this interdisciplinary field requires a common ground to succeed. Second, our analysis shows that the process orientation of the service systems worldview needs further development. More precisely, more elaborate service process models than ISPAR could be developed to account for the more detailed service interaction typologies proposed by some of the frameworks discussed in the paper. 
Towards a Service System Ontology for Service Science

\section{References}

1. IfM, IBM: Succeeding through service innovation: a service perspective for education, research, business and government. University of Cambridge Institute for Manufacturing, Cambridge (2008)

2. Alter, S.: Service system fundamentals: Work system, value chain, and life cycle. IBM Systems Journal 47, 71-85 (2010)

3. Vargo, S.L., Maglio, P.P., Akaka, M.A.: On value and value co-creation: A service systems and service logic perspective. European management journal 26, 145-152 (2008)

4. Spohrer, J., Kwan, S.K.: Service Science, Management, Engineering, and Design (SSMED): An Emerging Discipline-Outline \& References. International Journal of Information Systems in the Service Sector (IJISSS) 1, 1-31 (2009)

5. Spohrer, J., Maglio, P.P.: Service Science: Towards a Smarter Planet. In: Salvendy, G., Karwowski, W. (eds.) Introduction to Service Engineering. John Wiley \& Sons (2010)

6. Spohrer, J., Anderson, L., Pass, N., Ager, T.: Service science and service-dominant logic. In: Otago Forum 2: Academis papers, pp. 4-18. (2008)

7. Spohrer, J., Golinelli, G.M., Piciocchi, P., Bassano, C.: An Integrated SS-VSA Analysis of Changing Job Roles. Service Science 2(1/2), pp 1-20 (2010)

8. Maglio, P.P., Vargo, S.L., Caswell, N., Spohrer, J.: The service system is the basic abstraction of service science. Information Systems and e-business Management 7, 395-406 (2009)

9. Chesbrough, H., Spohrer, J.: A research manifesto for services science. Communications of the ACM 49, 35-40 (2006)

10.Maglio, P.P., Srinivasan, S., Kreulen, J.T., Spohrer, J.: Service systems, service scientists, SSME, and innovation. Communications of the ACM 49, 81-85 (2006)

11.Spohrer, J., Maglio, P.P., Bailey, J., Gruhl, D.: Steps toward a science of service systems. Computer 40, 71-77 (2007)

12.Barile, S., Spohrer, J., Polese, F.: System Thinking for Service Research Advances. Service Science 2, (2010)

13.Mora, M., S., R.M., Rory, O.C., Gelman, O.: Toward an Integrated Conceptualization of the service and Service system Concepts: A systems approach. International Journal of Information Systems in the Service Sector (IJISSS) 1, 36-57 pp (2009)

14.Ferrario, R., Guarino, N.: Towards an ontological foundation for services science. Future Internet-FIS 2008 152-169 (2009)

15.Vargo, S., Lusch, R.: Evolving to a new dominant logic for marketing. Journal of marketing 68, 1-17 (2004)

16.Vargo, S., Lusch, R.: From goods to service (s): Divergences and convergences of logics. Industrial Marketing Management 37, 254-259 (2008)

17.Lusch, R., Vargo, S., Wessels, G.: Toward a conceptual foundation for service science: Contributions from service-dominant logic. IBM Systems Journal 47, 5-14 (2010)

18.Sampson, S., Froehle, C.: Foundations and implications of a proposed unified services theory. Production and Operations Management 15, 329 (2006)

19.Alter, S.: The work system method: connecting people, processes, and IT for business results. Work System Press (2006)

20.Parasuraman, A., Zeithaml, V., Berry, L.: A conceptual model of service quality and its implications for future research. The Journal of Marketing 49, 41-50 (1985)

21.Wild, P.J.: A systemic framework for supporting cross-disciplinary efforts in services research. CIRP Journal of Manufacturing Science and Technology (2010) 